JOURNAL OF SYNCHROTRON RADIATION

ISSN 1600-5775

Received 18 March 2020

Accepted 28 April 2020

Edited by S. Svensson, Uppsala University, Sweden

Keywords: soft X-ray absorption spectroscopy; low-energy region; argon gas window; atmospheric conditions.
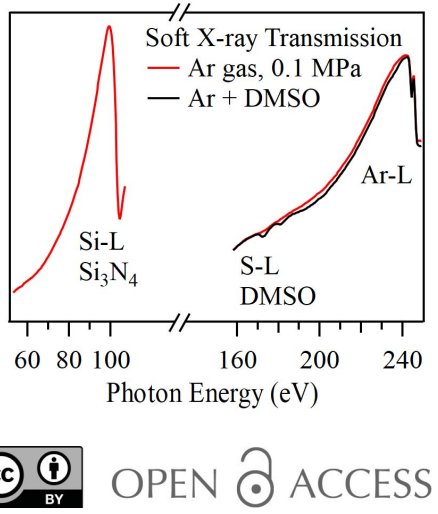

\section{Soft X-ray absorption spectroscopy in the low-energy region explored using an argon gas window}

\author{
Masanari Nagasaka*
}

Institute for Molecular Science, Myodaiji, Okazaki 444-8585, Japan, and SOKENDAI (The Graduate University for Advanced Studies), Myodaiji, Okazaki 444-8585, Japan. *Correspondence e-mail: nagasaka@ims.ac.jp

The soft X-ray region below $200 \mathrm{eV}$ is important for investigating chemical and biological phenomena since it covers $K$-edges of Li and $\mathrm{B}$ and $L$-edges of $\mathrm{Si}, \mathrm{P}$, $\mathrm{S}$ and $\mathrm{Cl}$. Helium gas is generally used as the soft $\mathrm{X}$-ray transmission window for soft X-ray absorption spectroscopy (XAS) under atmospheric conditions. However, the helium gas window cannot be applied to XAS in the low-energy region since transmitted soft X-rays mostly consist of high-order X-rays due to the low transmission of first-order X-rays. In this study, the argon gas window is proposed as a new soft X-ray transmission window in the low-energy region. High-order X-rays are removed by the absorption of the Ar $L$-edge $(240 \mathrm{eV})$, and first-order X-rays become the major contribution of transmitted soft X-rays in the low-energy region. Under atmospheric argon conditions, the doubleexcitation Rydberg series of helium gas $(60 \mathrm{eV})$, Si $L$-edge XAS of an $\mathrm{Si}_{3} \mathrm{~N}_{4}$ membrane $(100 \mathrm{eV})$ and $\mathrm{S} L$-edge XAS of dimethyl sulfoxide gas $(170 \mathrm{eV})$ are successfully measured, indicating that the argon gas window is effective for soft $\mathrm{X}$-ray transmission in the low-energy region from $60 \mathrm{eV}$ to $240 \mathrm{eV}$.

\section{Introduction}

Soft X-ray absorption spectroscopy (XAS) is an elementspecific method used to investigate local electronic structures of materials since it observes the excitation process of a core electron to unoccupied orbitals (Stöhr, 1992). Since soft X-rays are strongly absorbed by air and liquids, XAS spectra of gas and solid samples under ultrahigh-vacuum conditions have been studied extensively. Recently, several groups have measured XAS spectra under atmospheric conditions using the high soft X-ray transmission of helium gas (Chantler, 2000). A differential pumping system is used between a soft $\mathrm{X}$-ray beamline under ultrahigh-vacuum conditions and a measurement chamber under atmospheric helium conditions (Lee et al., 2001; Gog et al., 2007; Tamenori, 2010). X-ray photoelectron spectroscopy has also been developed for the measurement of samples near ambient atmospheric pressure (Takagi et al., 2017), and is applied to the analyses of catalytic reactions (Kondoh et al., 2016) and fuel cells (Takagi et al., 2018).

As discussed above, the helium gas window is generally used for soft X-ray transmission. The water window at the energy region from the $\mathrm{C} K$-edge $(280 \mathrm{eV})$ to the $\mathrm{O} K$-edge $(530 \mathrm{eV})$ is widely used for microscopic measurements of biomaterials in aqueous solutions (Ford et al., 1991) and ultrafast spectroscopy using high harmonic generation (Spielmann, 1997; Takahashi et al., 2008). Recently, XAS has been applied extensively to liquids and solutions in the soft 
X-ray region (Smith \& Saykally, 2017). $\mathrm{Si}_{3} \mathrm{~N}_{4}$ membranes with a thickness of $100 \mathrm{~nm}$ are widely used for XAS of liquid samples in transmission mode (Yang \& Kirz, 1987). Several groups measured XAS of liquid samples in transmission mode by packing liquid samples with $\mathrm{Si}_{3} \mathrm{~N}_{4}$ membranes (Näslund $e t$ al., 2005; Schreck et al., 2011; Meibohm et al., 2014; Sellberg et al., 2014). We have also developed a transmission-type liquid flow cell for XAS of liquid samples (Nagasaka et al., 2020a). The liquid layer is sandwiched between two $\mathrm{Si}_{3} \mathrm{~N}_{4}$ membranes and the liquid thickness is controllable from $2000 \mathrm{~nm}$ to $20 \mathrm{~nm}$ by controlling the helium pressure around the liquid cell from $0.1 \mathrm{MPa}$ to $0.12 \mathrm{MPa}$ (Nagasaka et al., 2018a). In aqueous solutions, molecular interactions of solute organic molecules are measured by $\mathrm{C}$ and $\mathrm{N} K$-edge XAS, and those of water are separately observed by $\mathrm{O} K$-edge XAS (Nagasaka et al., $2018 b, 2020 b$ ). XAS is also applied to in situ/operando observations of catalytic (Yuzawa et al., 2015) and electrochemical reactions (Nagasaka et al., 2013, 2014).

On the other hand, the low-energy region below $200 \mathrm{eV}$ includes important absorption edges for the investigation of chemical and biological phenomena such as the $K$-edges of $\mathrm{Li}$ and $\mathrm{B}$ and the $L$-edges of $\mathrm{Si}, \mathrm{P}, \mathrm{S}$ and $\mathrm{Cl}$. In soft X-ray beamlines at synchrotron radiation facilities, monochromatic soft X-rays include not only first-order X-rays but also highorder X-rays due to the high-order diffraction of plane-grating monochromators. XAS measurement below $200 \mathrm{eV}$ is difficult since transmitted soft $\mathrm{X}$-rays mostly consist of high-order $\mathrm{X}$-rays due to the low transmission of first-order X-rays (Chantler, 2000). For example, soft X-ray transmissions with photon energies of $160 \mathrm{eV}, 190 \mathrm{eV}, 400 \mathrm{eV}$ and $530 \mathrm{eV}$ are $11 \%, 22 \%, 82 \%$ and $93 \%$, respectively, for a $1 \mathrm{~cm}$ propagation under atmospheric helium conditions. High-order X-rays are usually removed by metal filters, by energy analysis using a silicon drift detector (Lechner et al., 1996), and by controlling the incident angle of a focused mirror in the beamline (Kitajima et al., 1999). However, it is technically difficult to detect first-order X-rays below $200 \mathrm{eV}$ without the contribution of high-order X-rays.

In this study, we propose the argon gas window for XAS in the low-energy region. Previously, the argon gas window would have been mainly used for the transmission of vacuum ultraviolet light (Mercier et al., 2000; Giuliani et al., 2011). It is also used as a band-pass filter that removes soft $\mathrm{X}$-rays below $40 \mathrm{eV}$ by filling with a small amount of argon gas $(50 \mathrm{~Pa})$ under vacuum conditions (Makimura $e t$ al., 2006). On the other hand, the argon gas window is expected to obtain firstorder X-rays in the low-energy region by removing the high-order $\mathrm{X}$-rays above $240 \mathrm{eV}$ with the absorption of the Ar $L$-edge (Sairanen et al., 1996). Soft $\mathrm{X}$-ray transmission measurements of helium and argon gas have been performed for the evaluation of the argon gas window.

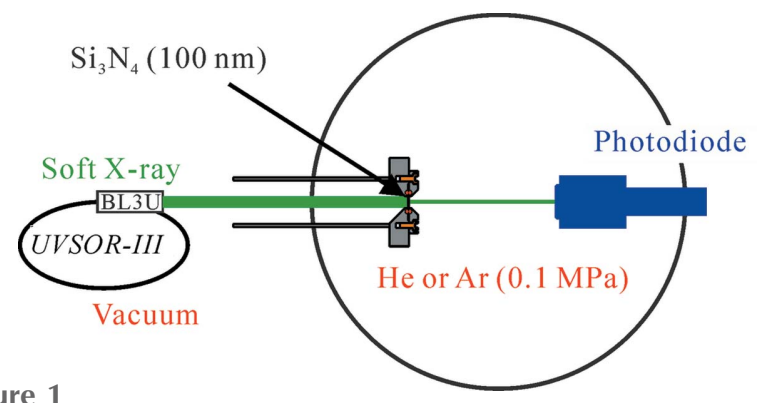

Schematic of the soft X-ray transmission measurements of helium or argon gas in the low-energy region. Details are given in the text.

\section{Experimental methods}

Experiments were performed at the soft X-ray undulator beamline BL3U at the UVSOR-III synchrotron (Hatsui, 2004). Fig. 1 shows a schematic of the experimental setup. This system consists of two chambers under ultrahigh vacuum and atmospheric helium or argon conditions. The two chambers are separated by an $\mathrm{Si}_{3} \mathrm{~N}_{4}$ membrane with a thickness of $100 \mathrm{~nm}$ and a window size of $200 \mu \mathrm{m} \times 200 \mu \mathrm{m}$ (NTT-AT). The vacuum chamber is connected to the soft X-ray beamline. In the atmospheric chamber, helium or argon gas is flowed using a mass flow controller (Kofloc). Two gas samples can be mixed at any mixing ratio by the combination of two mass flow controllers. Soft X-rays under vacuum pass through the $\mathrm{Si}_{3} \mathrm{~N}_{4}$ membrane window, the atmospheric helium or argon environments, and finally reach a photodiode detector (Opto Diode AXUV100G). The distance between the $\mathrm{Si}_{3} \mathrm{~N}_{4}$ membrane and the photodiode detector is estimated to be $41 \mathrm{~mm}$, which is sufficient to include our transmission-type liquid flow cell (Nagasaka et al., 2018a).

\section{Results and discussion}

Fig. 2 shows soft X-ray transmission spectra of helium gas in the low-energy region. Fig. 2(a) shows the energy region from $53 \mathrm{eV}$ to $107 \mathrm{eV}$. The energy resolution is set to $E / \Delta E=1000$ at $100 \mathrm{eV}$. We expect to observe the double-excitation resonance state of helium gas $(61 \mathrm{eV})$ (Domke et al., 1996). We also expect to observe the $\mathrm{Si} L$-edge XAS peak of the $\mathrm{Si}_{3} \mathrm{~N}_{4}$ 
membrane $(100 \mathrm{eV})$ (Tanaka et al., 2001), which separates the atmospheric chamber from the beamline under ultrahigh vacuum conditions. However, the XAS peaks of both helium gas and the $\mathrm{Si}_{3} \mathrm{~N}_{4}$ membrane are not observed in the transmission spectrum of helium gas. Although small peaks at $80 \mathrm{eV}$ and $100 \mathrm{eV}$ are observed, these peaks can be derived from the absorption of the $\mathrm{Si}_{3} \mathrm{~N}_{4}$ membrane from the fifth- and fourth-order X-rays at the $\mathrm{N} K$-edge $(400 \mathrm{eV})$, respectively. The transmission spectrum of first-order $\mathrm{X}$-rays is not obtained under atmospheric helium conditions since the ratio of the high-order X-rays is extremely high in this energy region.

Fig. 2(b) shows the soft X-ray transmission spectrum of helium gas in the energy region from $158 \mathrm{eV}$ to $249 \mathrm{eV}$. The energy resolution is set to $E / \Delta E=1000$ at $200 \mathrm{eV}$. The absorption peak around $200 \mathrm{eV}$ can be attributed to the absorption of second-order $\mathrm{X}$-rays by the $\mathrm{Si}_{3} \mathrm{~N}_{4}$ membrane at the $\mathrm{N} K$-edge. On the other hand, we also measured soft $\mathrm{X}$-ray transmission spectra of the mixture of dimethyl sulfoxide (DMSO) and helium gas, in which a small amount of DMSO gas is formed by bubbling liquid DMSO with helium gas. However, there are no spectral differences between DMSO/ $\mathrm{He}$ mixed gas and pure helium gas in the $\mathrm{S} L$-edge $(170 \mathrm{eV})$, although the DMSO molecule contains a sulfur atom. The absorption of first-order X-rays is also not observed at $170 \mathrm{eV}$ as the transmitted soft X-rays mostly consist of high-order $\mathrm{X}$-rays. As a result, it is impossible to measure XAS under atmospheric helium conditions in the low-energy region below $200 \mathrm{eV}$.

Fig. 3 shows the soft X-ray transmission spectra of argon gas in the low-energy region. Fig. 3(a) shows the energy region from $53 \mathrm{eV}$ to $107 \mathrm{eV}$. Argon gas has the role to remove highorder X-rays above $240 \mathrm{eV}$ due to the absorption of the $\mathrm{Ar}$ $L$-edge. That is why the small peaks at $80 \mathrm{eV}$ and $100 \mathrm{eV}$ observed in Fig. 2(a) are completely diminished in the transmission spectrum of argon gas since these peaks are derived from the absorption of the $\mathrm{Si}_{3} \mathrm{~N}_{4}$ membrane from the fifth- and fourth-order $\mathrm{X}$-rays at the $\mathrm{N} K$-edge. The spectrum also shows the absorption peak of the $\mathrm{Si}_{3} \mathrm{~N}_{4}$ membrane around $104 \mathrm{eV}$ at the Si $L$-edge. Fig. 3(b) shows the energy region from $158 \mathrm{eV}$ to $249 \mathrm{eV}$. The absorption of argon gas is observed at $244 \mathrm{eV}$ at the Ar $L$-edge. When a small amount of DMSO gas was mixed
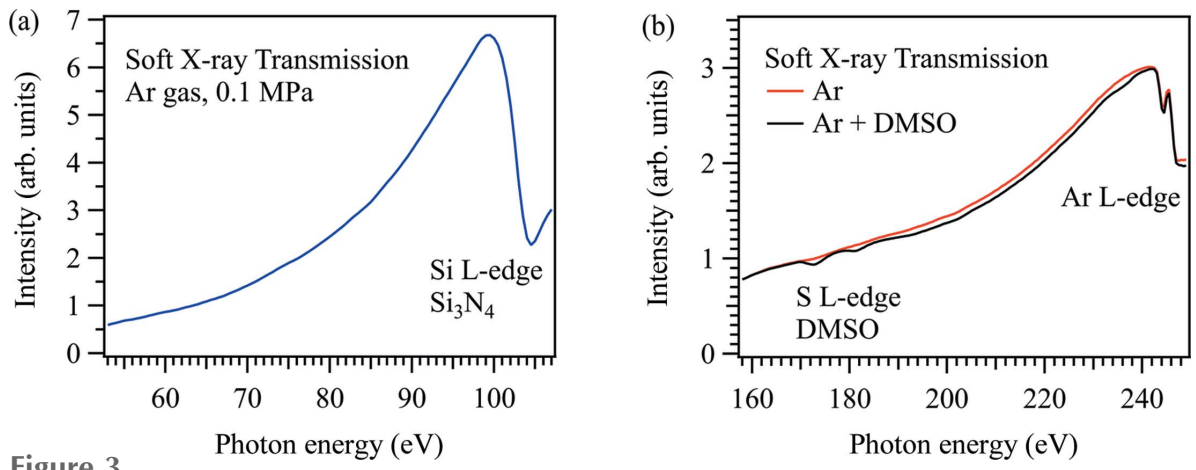

Soft X-ray transmission spectra of argon gas under atmospheric conditions in the energy region $(a)$ from $53 \mathrm{eV}$ to $107 \mathrm{eV}$ and $(b)$ from $158 \mathrm{eV}$ to $249 \mathrm{eV}$. The transmission spectrum of argon gas mixed with DMSO gas is also shown.

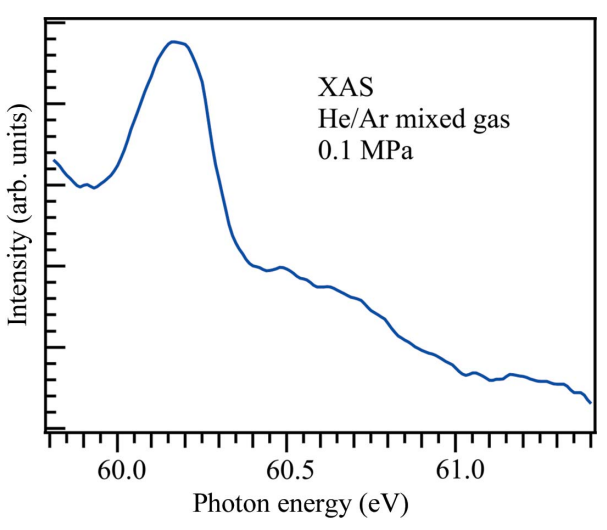

Figure 4

XAS spectrum of helium gas mixed with argon gas under atmospheric conditions.

with the argon gas, we successfully observed the absorption peaks of DMSO gas at the $\mathrm{S} L$-edge $(170 \mathrm{eV})$, which clearly demonstrates the spectral difference between DMSO/Ar mixed gas and pure argon gas. Although the photon flux of the transmitted soft $\mathrm{X}$-rays in argon gas is much smaller than that in helium gas (Chantler, 2000), the intensity change of the first-order X-rays is clearly observed. This is because soft $\mathrm{X}$-rays above $240 \mathrm{eV}$ are completely removed by argon gas due to the $\operatorname{Ar} L$-edge.

Fig. 4 shows the XAS spectrum of helium gas, where a small amount of helium gas is mixed under atmospheric argon conditions. The energy resolution is set to $E / \Delta E=1000$ at $60 \mathrm{eV}$. The XAS spectrum is derived using the Beer-Lambert law, $\ln \left(I_{0} / I\right)$, where $I_{0}$ and $I$ are the transmission signals of argon gas and $\mathrm{Ar} / \mathrm{He}$ mixed gas, respectively. The spectrum shows the helium resonance energy $E_{2}$ of the $n=2$ doubleexcitation Rydberg series at $60.147 \mathrm{eV}$ (Domke et al., 1996). Since Li $K$-edge XAS spectra show peaks around $60 \mathrm{eV}$ (O'Shaughnessy et al., 2018), the measurement of Li $K$-edge XAS under atmospheric conditions is possible using the argon gas window. As a result, the argon gas window enables us to measure XAS under atmospheric conditions in the low-energy region from $60 \mathrm{eV}$ to $240 \mathrm{eV}$. 
Rydberg series of helium gas $(60 \mathrm{eV})$, Si $L$-edge XAS of the $\mathrm{Si}_{3} \mathrm{~N}_{4}$ membrane $(100 \mathrm{eV})$ and $\mathrm{S} L$-edge XAS of DMSO gas $(170 \mathrm{eV})$. We expect that the argon gas window will become the standard soft X-ray transmission window, as the helium gas window transmits soft $\mathrm{X}$-rays above the $\mathrm{C} K$-edge $(280 \mathrm{eV})$ and the water window in the energy region between the $\mathrm{C}$ $K$-edge and the $\mathrm{O} K$-edge $(530 \mathrm{eV})$.

In our transmitted-type liquid flow cell, the liquid thickness is controlled by adjusting the helium pressure from $0.1 \mathrm{MPa}$ to $0.12 \mathrm{MPa}$ for XAS of liquid samples in transmission mode (Nagasaka et al., 2018a). When the buffer gas is changed to argon gas, we expect to be able to measure XAS of liquid samples in the low-energy region below $200 \mathrm{eV}$. XAS can be applied to the investigation of several catalytic and electrochemical reactions such as Li $K$-edge XAS of the lithium ion battery (Thackeray, 1997), S $L$-edge XAS of Nafion polymer films in a fuel cell electrode (Masuda et al., 2013) and B $K$ edge XAS of the nickel borate electrocatalyst for oxygen evolution reactions (Dincă et al., 2010). The application of biological phenomena is also expected, such as molecular interactions of phosphate ions with water in liquid bilayers around biological membranes (Tero et al., 2017) from P $L$-edge XAS. Consequently, XAS in the low-energy region has the potential to enhance our understanding of physical, chemical and biological phenomena in solution, which would be realized by the argon gas window.

\section{Acknowledgements}

The authors are grateful to the staff members of UVSOR-III synchrotron for their kind support.

\section{Funding information}

The following funding is acknowledged: Japan Society for the Promotion of Science (grant No. JP19H02680); National Institutes of Natural Sciences (grant No. 01421703; grant No. 01211907); Murata Science Foundation.

\section{References}

Chantler, C. T. (2000). J. Phys. Chem. Ref. Data, 29, 597-1056.

Dincă, M., Surendranath, Y. \& Nocera, D. G. (2010). Proc. Natl Acad. Sci. USA, 107, 10337-10341.

Domke, M., Schulz, K., Remmers, G., Kaindl, G. \& Wintgen, D. (1996). Phys. Rev. A, 53, 1424-1438.

Ford, T. W., Stead, A. D. \& Cotton, R. A. (1991). Electron Microsc. Rev. 4, 269-292.

Giuliani, A., Yao, I., Lagarde, B., Rey, S., Duval, J.-P., Rommeluere, P., Jamme, F., Rouam, V., Wein, F., De Oliveira, C., Ros, M., Lestrade, A., Desjardins, K., Giorgetta, J.-L., Laprevote, O., Herbaux, C. \& Refregiers, M. (2011). J. Synchrotron Rad. 18, 546-549.

Gog, T., Casa, D. M., Kuzmenko, I., Krakora, R. J. \& Bolin, T. B. (2007). J. Synchrotron Rad. 14, 339-344.

Hatsui, T., Shigemasa, E. \& Kosugi, N. (2004). AIP Conf. Proc. 705, 921-924.
Kitajima, Y., Yonamoto, Y., Amemiya, K., Tsukabayashi, H., Ohta, T. \& Ito, K. (1999). J. Electron Spectrosc. 101-103, 927-929.

Kondoh, H., Toyoshima, R., Monya, Y., Yoshida, M., Mase, K., Amemiya, K. \& Mun, B. S. (2016). Catal. Today, 260, 14-20.

Lechner, P., Eckbauer, S., Hartmann, R., Krisch, S., Hauff, D., Richter, R., Soltau, H., Strüder, L., Fiorini, C., Gatti, E., Longoni, A. \& Sampietro, M. (1996). Nucl. Instrum. Methods Phys. Res. A, 377, 346-351.

Lee, J. C., Ueng, T. S., Chen, J. R., Hsu, Y. J., Hsiung, G. Y., Lin, T. F., Chang, S. H., Hsu, S. N. \& Wang, D. J. (2001). Nucl. Instrum. Methods Phys. Res. A, 467-468, 793-796.

Makimura, T., Uchida, S., Murakami, K. \& Niino, H. (2006). Appl. Phys. Lett. 89, 101118.

Masuda, T., Fukumitsu, H., Kondo, T., Naohara, H., Tamura, K., Sakata, O. \& Uosaki, K. (2013). J. Phys. Chem. C, 117, 1216812171.

Meibohm, J., Schreck, S. \& Wernet, P. (2014). Rev. Sci. Instrum. 85, 103102.

Mercier, B., Compin, M., Prevost, C., Bellec, G., Thissen, R., Dutuit, O. \& Nahon, L. (2000). J. Vac. Sci. Technol. A, 18, 2533-2541.

Nagasaka, M., Yuzawa, H., Horigome, T., Hitchcock, A. P. \& Kosugi, N. (2013). J. Phys. Chem. C, 117, 16343-16348.

Nagasaka, M., Yuzawa, H., Horigome, T. \& Kosugi, N. (2014). Rev. Sci. Instrum. 85, 104105.

Nagasaka, M., Yuzawa, H., Horigome, T. \& Kosugi, N. (2018a). J. Electron Spectrosc. Relat. Phenom. 224, 93-99.

Nagasaka, M., Yuzawa, H. \& Kosugi, N. (2018b). Z. Phys. Chem. 232, 705-722.

Nagasaka, M., Yuzawa, H. \& Kosugi, N. (2020a). Anal. Sci. 36, 95-105.

Nagasaka, M., Yuzawa, H. \& Kosugi, N. (2020b). J. Phys. Chem. B, 124, 1259-1265.

Näslund, L. Å., Lüning, J., Ufuktepe, Y., Ogasawara, H., Wernet, P., Bergmann, U., Pettersson, L. G. M. \& Nilsson, A. (2005). J. Phys. Chem. B, 109, 13835-13839.

O'Shaughnessy, C., Henderson, G. S., Moulton, B. J. A., Zuin, L. \& Neuville, D. R. (2018). J. Synchrotron Rad. 25, 543-551.

Sairanen, O.-P., Kivimäki, A., Nõmmiste, E., Aksela, H. \& Aksela, S. (1996). Phys. Rev. A, 54, 2834-2839.

Schreck, S., Gavrila, G., Weniger, C. \& Wernet, P. (2011). Rev. Sci. Instrum. 82, 103101.

Sellberg, J. A., Kaya, S., Segtnan, V. H., Chen, C., Tyliszczak, T., Ogasawara, H., Nordlund, D., Pettersson, L. G. M. \& Nilsson, A. (2014). J. Chem. Phys. 141, 034507.

Smith, J. W. \& Saykally, R. J. (2017). Chem. Rev. 117, 13909-13934.

Spielmann, C. (1997). Science, 278, 661-664.

Stöhr, J. (1992). NEXAFS Spectroscopy. Berlin: Springer.

Takagi, Y., Nakamura, T., Yu, L., Chaveanghong, S., Sekizawa, O., Sakata, T., Uruga, T., Tada, M., Iwasawa, Y. \& Yokoyama, T. (2017). Appl. Phys. Expr. 10, 076603.

Takagi, Y., Uruga, T., Tada, M., Iwasawa, Y. \& Yokoyama, T. (2018). Acc. Chem. Res. 51, 719-727.

Takahashi, E. J., Kanai, T., Ishikawa, K. L., Nabekawa, Y. \& Midorikawa, K. (2008). Phys. Rev. Lett. 101, 253901.

Tamenori, Y. (2010). J. Synchrotron Rad. 17, 243-249.

Tanaka, I., Mizoguchi, T., Sekine, T., He, H., Kimoto, K., Kobayashi, T., Mo, S.-D. \& Ching, W. Y. (2001). Appl. Phys. Lett. 78, 21342136.

Tero, R., Fukumoto, K., Motegi, T., Yoshida, M., Niwano, M. \& Hirano-Iwata, A. (2017). Sci. Rep. 7, 17905.

Thackeray, M. M. (1997). Prog. Solid State Chem. 25, 1-71.

Yang, B. X. \& Kirz, J. (1987). Phys. Rev. B, 36, 1361-1364.

Yuzawa, H., Nagasaka, M. \& Kosugi, N. (2015). J. Phys. Chem. C, 119, 7738-7745. 